\title{
Morphology of Larval Molting in the Pin Nematode, Paratylenchus aciculus BROWN (Nematoda: Paratylenchidae) with the Emphasis on Stylet Regeneration
}

\author{
Tomotoshi KAshio', Nobuyoshi Ishibashi and Tamio YoKoo \\ Lab. of Nematology and Entomology, Faculty of Agriculture, Saga University, Saga 840, Japan
}

(Received December 9, 1974)

\begin{abstract}
Morphology of the molting process and stylet regeneration of larvae of the pin nematode, Paratylenchus aciculus, was investigated. Numerous refractive granules appeared around the oesophageal region accompanying a disappearance of the stylet in second stage larvae. These granules disappeared in fourth stage larvae. The period of the third larval stage was found to be very short. Stylets formed by third and fourth stage larvae did not appear to be functional, and, accordingly, feeding was not considered to be essential for these larval stages. Regeneration of the stylet during the fourth molting occurred only in the female. Regeneration of the stylet advanced reverse in the dissolution of the stylet in the second molting.
\end{abstract}

\section{INTRODUGTION}

RhoAdes and Linford $(1959,1961)$ showed that the stylet of fourth stage larvae of Paratylenchus projectus and $P$. dianthus are weakly refractive, short, slender and with a single small basal swelling. RASKI (1962) also demonstrated lack of a functional stylet in third or fourth stage larvae of Gracilacus spp. Kashio and Yokoo (1971) reported that no stylets were observed in the fourth stage larvae of $P$. aciculus. The significance of these phenomena still remains unknown, and no detailed description has been made on the molting of these nematodes.

The present study was conducted in order to discern the process of molting and stylet regeneration in the pin nematode, $P$. aciculus, with particular reference to clarification of mechanisms occurring between the third stage and adulthood.

\section{MATERIALS AND METHODS}

$P$. aciculus used in this study was collected from the mulberry field of the Kyushu Branch Sericultural Experimental Station at Ueki, Kumamoto in 1969, and was kept in pots $(30 \mathrm{~cm}$ diam.) with the mulberry seedlings in a green house. The young female adults were extracted by the Baermann funnel method from soil. Nematodes were subjected to surface-sterilization with a $0.1 \%$ phenylmercuric chloride solution for 2$3 \mathrm{~min}$ and with a $2000 \mathrm{ppm}$ streptmycin solution for $5 \mathrm{~min}$., followed by 3 or 4 washings

1 Present address: Entomological Laboratory, Kuchinotsu Branch, Fruit Tree Research Station, Kuchinotsu, Minamitakakigun, Nagasaki 859-25, Japan. 
with sterilized water, and subsequently reared aseptically on seedlings of red clover which had been raised in petri dishes $(6 \mathrm{~cm}$ diam.) containing nutrient agar medium $(0.1 \%$ Hyponex, commercial fertilizer, in $0.75 \%$ water agar) at $\mathrm{pH} 6.2$. Petri dishes were placed in a growth chamber at $25^{\circ} \mathrm{C}$ under a daily photoperiod of 12 hours illumination followed by 12 hours of darkness. Second stage larvae used for observation were obtained from this aseptic culture, while fourth stage larvae were extracted from the soil by the centrifugal floatation technique. A number of second stage or fourth stage larvae were placed in a drop of $1.0 \%$ water agar applied to depressed glass slides. Cover slips were mounted and sealed with white vaseline; a small opening was purposely left to allow for air exchange. These were incubated in petridishes with a moist filter paper to preclude the possibility of evaporation, and maintained at $25^{\circ} \mathrm{C}$ in the dark. Morphological observation was made at intervals of 3 hours at a magnification of $600 \times$ by killing nematodes with hot water $\left(40-50^{\circ} \mathrm{C}\right)$ and fixing with T.A.F. solution.

\section{RESULTS}

\section{Stylet dissolution}

Prior to molting, the body cavity of second stage larvae was filled with numerous refractive granules and became darkened. This was particularly apparent in the oesophageal region in comparison to newly hatched second stage larvae (Fig. 1 A, B). The nematode became less active and quiescent, displaying a characteristic hooklike posture. Following this phase, disappearance of the stylet and cuticular structure in the oesophageal region occurred in the following sequence; stylet knobs (Telorhabdion), stylet shaft (Metarhabdion to mesorhabdion), followed by disappearance of the median bulb including the valve, oesophageal canal and lumen (Fig. 1 B). Meanwhile, the
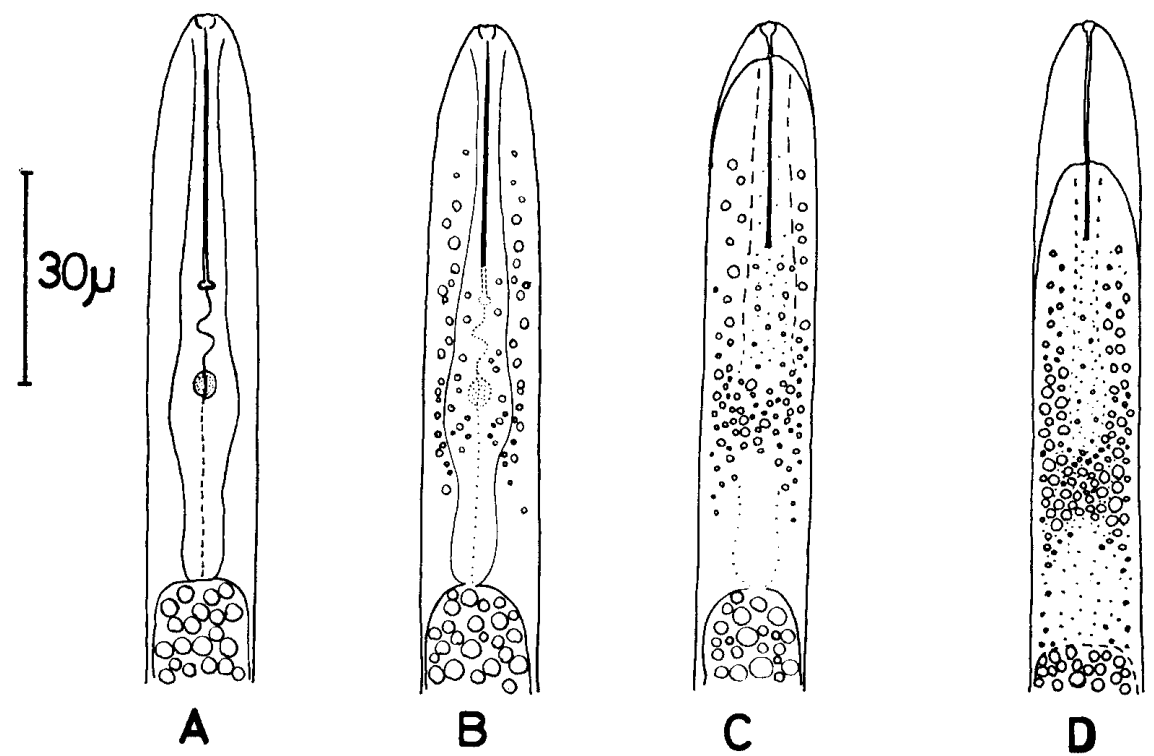

Fig. 1. Representation of the process of stylet dissolution in Paralylenchus aciculus. A: Anterior part of a second stage larva before molting; B: Appearance of granules in the oesophageal region; $\mathrm{C}$ : Disappearance of shaft and knobs of stylet from a third stage larva; $\mathrm{D}$ : Distribution of granules in the oesophageal region of a third stage larva. 


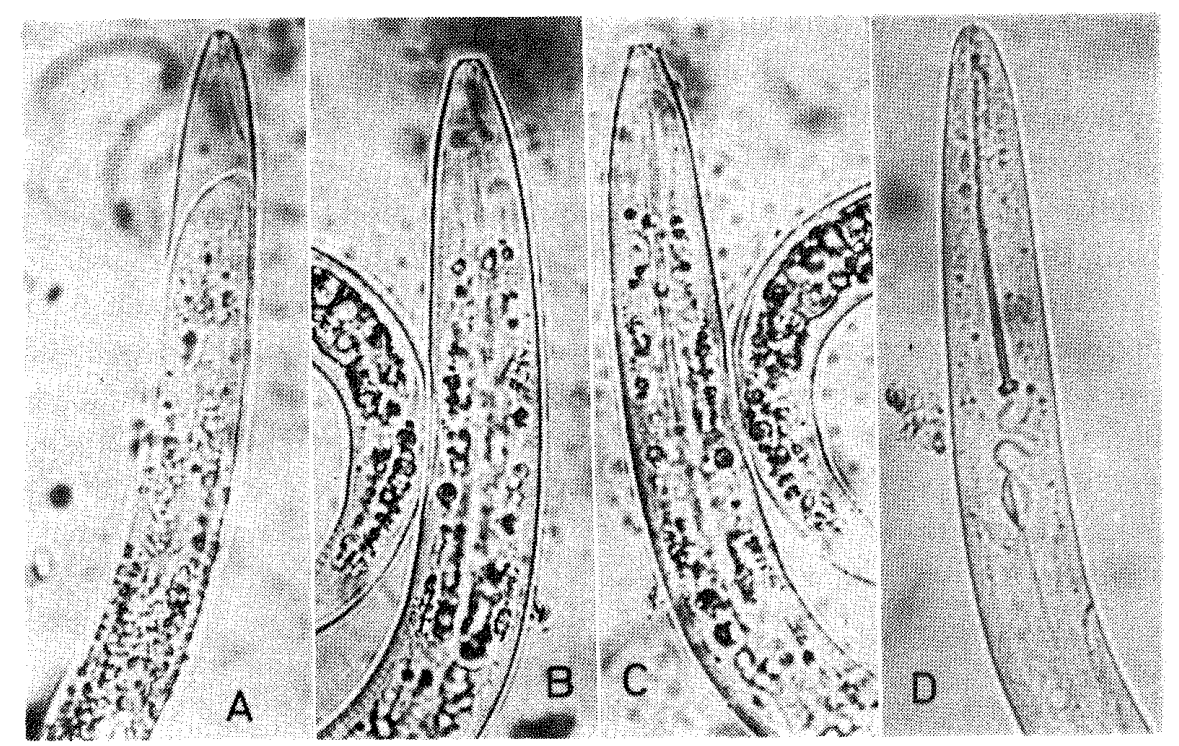

Fig. 2. Photomicrographs of stylets from larvae of the third and fourth stages of $P$. aciculus, showing the stylet dissolution and regeneration. A: Anterior part of a third stage larva showing the shedding of the second stage cuticle; B: Fourth stage larva before the fourth molt; $\quad \mathrm{C}$ : An early phase in the formation of the conical part of a stylet from an adult female; D: $\Lambda$ large stylet of an adult female.

cephalic framework of the third stage larva became visible and the lip region of cuticle of second stage larvae was detached with the conical part of the stylet (Prorhabdion) (Fig. 1 C). At that time when half of the anterior conical part of the stylet was detached from the anterior end of third stage larvae, the shaft and knobs were observed to completely disappear. The stylet of third stage larvae was invisible (Fig. 1 D; Fig. 2 A). Numerous refractive granules were seen in the body cavity except for that region which surrounds the amphidial pounches and the isthmus. The third stage larvae appeared to undergo the fourth stage in a short period; shedding of the cuticle of third stage larvae could not be observed. This may have been due to the adhesion of sheddings of the third stage larva to the new cuticle of that undergoing the fourth stage, and consequently the cuticle of the latter was appeared seen to be somewhat thicker and denser than that of the second stage larva. In fourth stage larvae, the location of the genital aperture gradually became hyaline (Fig. 3 A, B). The hyaline cavity was located at a position about $30 \%$ and $10 \%$ of the body length from the tail end, which corresponded to the position of the vulva and spicule respectively. Thus, the appearance of the hyaline cavity led to the discerning of sex.

\section{Stylet regeneration}

The period of the fourth larval stage varied depending upon the conditions under which the nematodes were placed. Prior to the fourth molting, the larvae again became less active, and later quiescent in a circular posture (Fig. $3 \mathrm{C}, \mathrm{D}$ ). The granules in the oesophageal region began to disappear and anterior part of the body became transparent (Fig. $4 \mathrm{~A}, \mathrm{~B}$ ). Six hours after commencement of the quiescent condition, initial formation of new epidermis in the adult was observed. The contraction of the adult body began from the cephalic framework of fourth stage larvae (Fig. 2 B; Fig. 4 B). 
Meanwhile, the granules in the oesophageal region gradually disappeared, at which time granules surrounding the median bulb were still observed, exhibiting an outline which was larger than that of the second stage larvae. In the female, formation of the stylet initiated the apex of the conical part 9-12 hours after quiescence took place, and the posterior structure of the new conical part of stylet was regenerated. The regeneration of the stylet proceeded in reverse of the dissolution of the stylet in the second molting. The conical part of the new stylet was completely formed during a period of about 9 hours, and a presumptive structure destined to form posterior parts was already visible at the end of this phase. The new stylet was about twice as long as that observed in second stage larvae (Fig. 2 D; Fig. 4 D). The granules around the median bulb gradually dissolved during the course of stylet formation. At this time, the oesophagus, median bulb, isthmus and posterior bulb became visible.

The regeneration of stylet as well as oesophagus were almost complete within 30-36 hours after the onset of the immobile condition of the larva. The new stylet became refractive and the nematode began to move actively.

Vulva and vagina were also formed during the fourth molting in the following process: a hyaline and semicircular portion in the body cavity of the fourth stage larva gradually extended into the dorsal area, and the invagination of the vulval slit appeared around the center of the hyaline portion. At this time, uterus and spermathecae were formed.

In the male, accompanying the formation of new cuticle, the granules in the anterior part of the body also began to disappear in a manner similar to that described

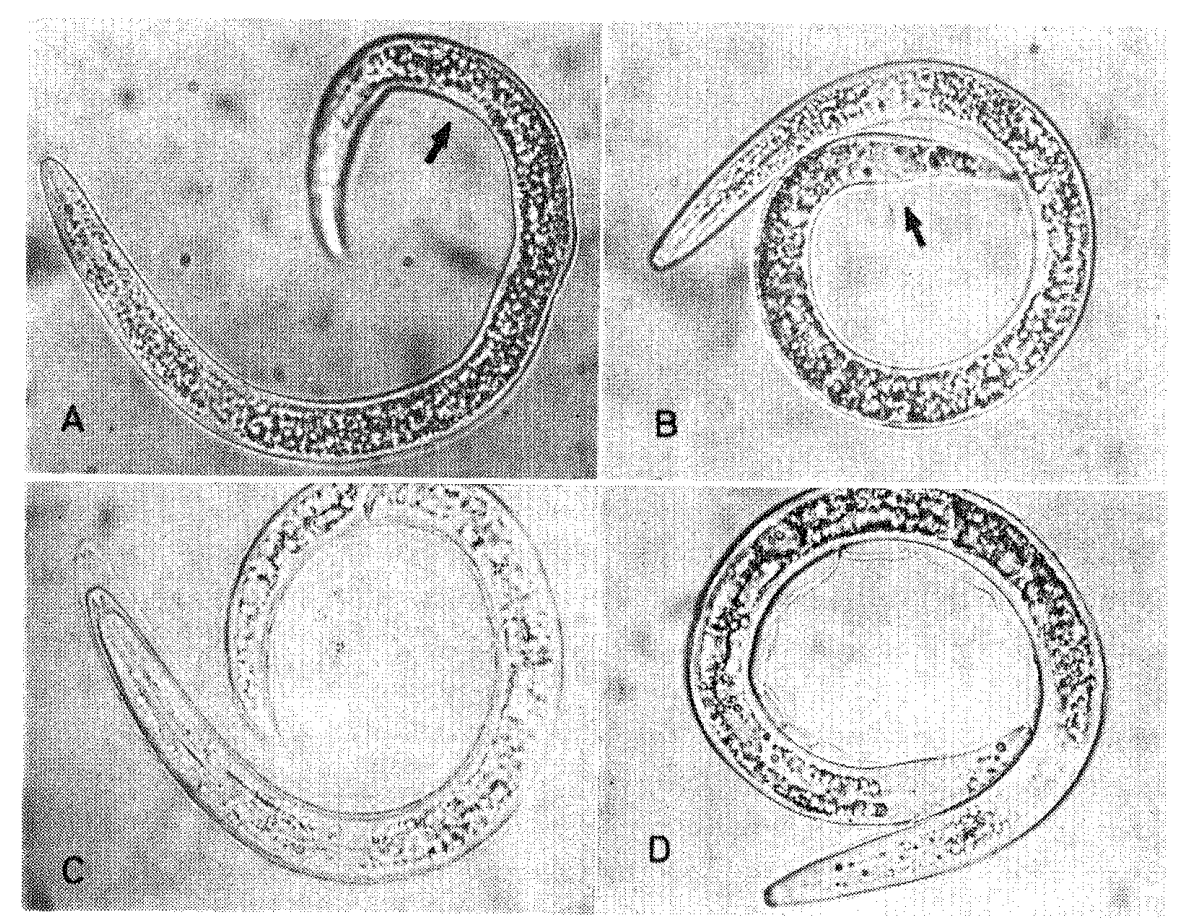

Fig. 3. Photomicrographs of fourth stage larvae in $P$. aciculus, showing the hyaline cavity around the genital aperture and the fourth molt. A: Female larva with a transparent vulval region (arrow); B: Male larva with a transparent spicule region (arrow); $\mathrm{C}$ : Adult female enclosed in shed cuticle of previous stages; D: Adult male without a stylet. 


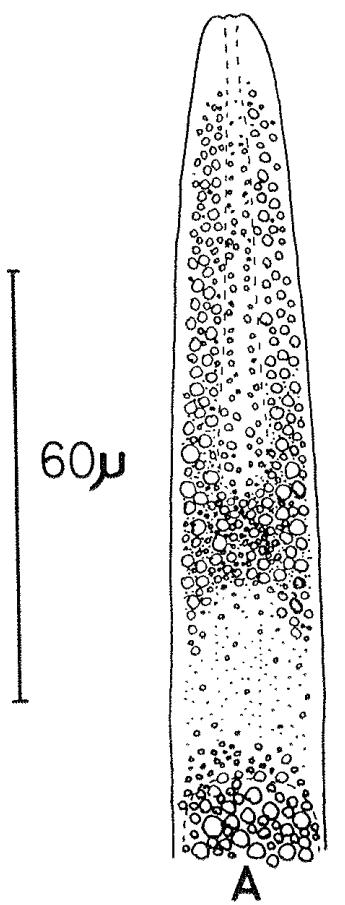

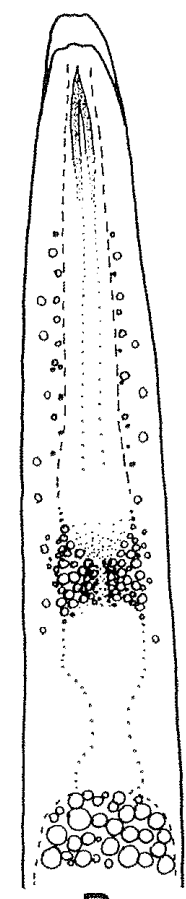

B

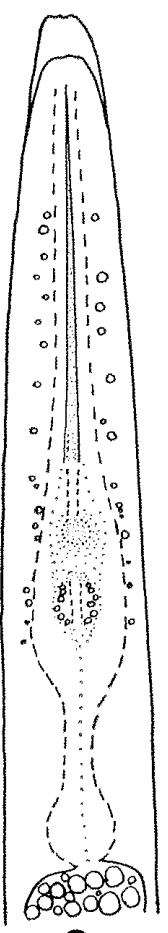

C

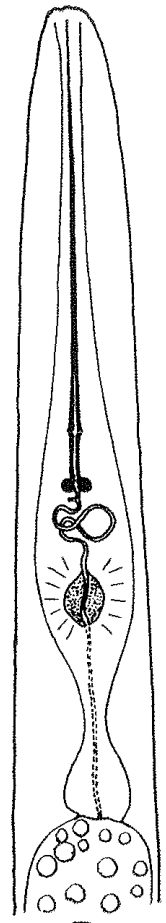

D

Fig. 4. Representation of the process of stylet regeneration in P. aciculus. A: Anterior part of a fourth stage larva; $B$ : The formation of the conical part of the stylet in an early phase, showing the shed cuticle of fourth stage larva; $\mathrm{C}$ : The formation of shaft and knobs of the stylet; 1): Anterior part of the adult female with a large stylet.

for the female, but the stylet and organs of oesophageal region were not regenerated. (Fig. $3 \mathrm{D})$. Formation of the spicules began on the ventral limb, followed by dorsal limb, and finally the manubrium and gubernaculum.

As the fourth molting advanced into the final phase, the circular posture of the nematode gradually transformed into a crescentic one, becoming more slender than in fourth stage larvae. The occasional twitching movement in the head and tail of the nematodes occurred more frequently. It took about 48 hours for the nematodes to complete their fourth molting after becoming quiescent.

In agar or distilled water, the old shed cuticles of the previous stages remained loose, being partially attached to the new cuticle at irregular intervals (Fig. 3 C, D). Some adults still possessed their shed cuticle of the second stage larvae.

The second stage larvae with refractive granules in the anterior part of body soon underwent succeeding molts in a water medium and attained the adult condition but did not become gravid when placed in agar without hosts or when left in distilled water. Larvae lacking such granules failed to molt and died within 12 days in water at $25^{\circ} \mathrm{C}$. Since third stage larvae were occasionally detected, it is speculated that these probably passed through this stage within a short period without feeding. The fourth stage larvae also did not feed, and most of them molted into adults when placed in distilled water for 15 days. 


\section{DISGUSSION}

As in other Tylenchids such as Radopholus similis (WEERdT, 1960), Ditylenchus destructor (Anderson and Daring, 1964), Pratylenchus spp. (Roman and Hirschmann, 1969) and Rotylenchulus reniformis (Nakasono, 1972, 1973), Paratylenchus aciculus underwent the same molting pattern described in the following: the nematodes became less active and quiescent while exhibiting a characteristic posture, the old cuticles were detached together with the previous conical part of stylets, and the posterior part of stylets and cuticular structures in the oesophgeal region faded. In most nematodes belonging to Tylenchida, formation of the new stylet begins immediately after the shedding of conical part of the old stylet. In P. aciculus, the matter of whether or not third stage larvae keep a functional stylet has been a question of considerable debate. RASKI (1962) and Kashio and Yokoo (1971) were unable to come up with a definitive answer. The present investigation has somewhat clarified the problem and has revealed that there is no functional stylet before molting of fourth stage larvae. Therefore, the stylet of both third and fourth stage larvae is invisible. Adhesion of the shedded cuticle of a third stage larva onto that of a fourth stage one might have given rise to the difficulty encountered in discrimination of the two stages. In Meloidogyne spp., it has been observed that the period of the third stage is so short (hour units), also that the shed cuticle of fourth stage male larva adheres to the cuticle of the adult stage which accordingly appears to emerge out after the third molting (TRIANTAPHYLLOW and Hirschmamm, 1960; Ishibashi, 1967).

When collected from dry soil, most of $P$. aciculus larvae which do not have stylets and do have hyaline cavities at the position of sex organ are fourth stage and not third stage, because according to this investigation, the fourth stage larvae are discriminated from the third one by the appearance of hyaline cavity. The undistinguishable shed cuticles of third stage larvae in the present investigation and scanty collection of them from soil may prove that the period of the third larval stage is very short.

It is also seen in Cacopaurus spp. and Gracilacus spp. (RAskI, 1962) that the adult stylet becomes twice as long as that of the second larval stage during the fourth molting. In other plant parasitic nematodes, the stylet gradually becomes larger with every molting, as seen in Xiphinema spp. (Coomans and Coninck, 1963), Ditylenchus destructor (Anderson and Daring, 1964) and Pratylenchus spp. (Roman and HirsahMANN, 1969).

Degeneration of the stylet and oesophagus in males during the molting process is also reported for Cacopaurus epacris by Allen and Jensen (1950) and for Hemicycliophora arenaria by vAN GUNDY (1959). Formation of spicules in P. aciculus is similar to that of Seinura spp. (Hechler and TAYlor, 1966), where the formation of spicules begins on the ventral limb, which is in contrast to Cylindrocorpus spp. (CHIN and TAYLor, 1970) where it proceeds on the dorsal limb.

It is considered that the feeding is essential for the second stage larvae to succeed in subsequent moltings, but it is unnecessary for the third and fourth stages. Kashio and Yoloo's previous report (1971) of the possible feeding of third stage larvae requires reexamination in view of the fact that RHOADES and LiNFoRd $(1959,1961)$ found that the preadult stage (fourth stage) or Paratylenchus projectus and $P$. dianthus can survive for a long period in moist soil without any host plants. Those of $P$. aciculus lacking stylets are also considered likely to survive without feeding for a long period. 


\section{AGKNOWLEDGEMENTS}

The authors wish to express their appreciation to Mr. E. Kondo, Laboratory of Nematology and Entomology, Faculty of Agriculture, Saga University, for valuable suggestions to this experiments. Cordial thanks are also due to Dr. M. IGhinore and Mr. K. Nakasono, National Institute of Agricultural Sciences, for criticism and correction of the manuscript.

\section{REFERENGES}

Allen, M. W. and H. J. Jensen (1950) Cacopaurus epacris, new species (Nematoda: Criconematidae), a nematode parasite of California black walnut roots. Proc. Helm. Soc. Wash. 17: 10-14.

Anderson, R. V. and H. M. Daring (1964) Spear development in Ditylenchus destructor Thorne. Nematologica 10: 131-135.

Ginin, D. A. and D. P. TAYloR (1970) Observation on moulting in species of Cylindrocorpus. Nematologica 16: $1-5$.

Coomans, A. and L. DE Coninck (1963) Observation on spear formation in Xiphinema. Nematologica 9: 85-96.

Hechler, H. G. and D. P. TAylor (1966) The moulting process in species of Seinura (Nematoda: Aphelenchoididae). Proc. Helm. Soc. Wash. 33: 90-96.

Ishrbashi, N. (1967) Studies on the propagation of the root-knot nematodes, Meloidogyne incognita (KofOID \& White, 1919). Jour. Cent. Agric. Exp. Stn No. 11: 177-219.

Kashio, T. and T. Yokoo (1971) Studies on the nemic-fauna of soil of the mulberry plant field in Kyushu. III. On the life history of pin nematode, Paratylenchus aciculus Brown, 1959. Agri. Bull. Saga Univ. 32: 57-61.

NAKasono, K. (1972) Development retardation and morphological abnormalities observed in moulting larvae of the reniform nematode, Rotylenchulus reniformis. Appl. Ent. Zool. 7: 243-245.

Nakasono, K. (1973) Studies on post-embryonic development of the reniform nematode, Rotylenchulus reniformis LINFORD and OliverRA (Nematoda: Rotylenchulidae) I. Morphological changes of the molting larva of a parthenogenetic population. Appl. Ent. Zool. 8: 83-96.

Raskr, D. J. (1962) Paratylenchidae n. fam. with descriptions of five new species of Gracilacus n. g. and an emendation of Cacopaurus Thorne, 1943, Paratylenchus Micoletzky, 1922 and Criconematidae Thorne, 1943. Proc. Helm. Soc. Wash. 29 : 189-207.

RhoAdes, H. L. and M. B. Linford (1959) Molting of pre-adult nematodes of the genus Paratylechus stimulated by root diffusates. Science 130: 1476-1477.

RhoAdes, H. L. and M. B. Linford (1961) Biological studies on some members of genus Paratylenchus. Proc. Helm. Soc. Wash. 28: 51-59.

Romam, J. and Hedwing Hirschmann (1966) Embryogenesis and postembryogenesis in species of Pratylenchus (Nematoda : Tylenchidae). Proc. Helm. Soc. Wash. 36: 164-174.

Triantaphyllow A. W. and Hedwing Hirschmann (1960) Post infection development of Meloidogyne incognita Chitwood, 1949. Ann. Inst. Phytopath. Benaki, N. S. 3: 1-11.

van Gundy, S. D. (1959) The life history of Hemicycliophora arenaria Raski. Proc. Helm. Soc. Wash. 26: 6772.

van Weerdt, L. G. (1960) Studies on the biology of Radopholus similis (Cobb, 1893) Thorne, 1949 III. Embryology and post embryonic development. Nematologica 5: 43-52. 